\title{
A interação em ambiente eletrônico no ensino de português língua estrangeira adicional: a otimização da aprendizagem de iniciantes
}

\author{
Lucia Rottava \\ Universidade Federal do Rio Grande do Sul \\ lucia.rottava@ufrgs.br \\ Antônio Márcio da Silva \\ University of Kent, UK \\ A.M.Da-Silva@kent.ac.uk
}

\section{Resumo}

Este artigo trata da interação em ambiente eletrônico, contemplando dois aspectos interligados: as possibilidades de interação por meio de recursos eletrônicos e a configuração do ensino e da aprendizagem de português como LE-adicional. O objetivo é analisar a produção oral e escrita de aprendizes de português LE-adicional. Os dados para a análise foram gerados em ambiente virtual. Os resultados sugerem alguns aspectos que os recursos eletrônicos otimizam: interação genuína; situações nas quais os aprendizes arriscam mais ao produzir na LE, alinhando-se ao que ocorre no cotidiano; aprendizagem para além da sala de aula, visto receberem feedback (retorno) do professor das construções na LE para além dos conteúdos programáticos; e autonomia aos aprendizes na medida em que podem sistematizar sua aprendizagem.

Palavras-chave: recursos eletrônicos; interação; português LE-adicional.

\begin{abstract}
This article discusses language learners' interaction in a virtual learning environment, contemplating two interconnected aspects: the possibilities of interaction through the use of electronic resources and the configuration of teaching and learning of Portuguese as an additional language (AL). The objective is to analyse learners of Portuguese-AL's oral and written production. The data analysed was produced in a virtual environment. The results suggest some aspects that electronic resources optimise: genuine interaction; situations in which learners risk more whist producing written and
\end{abstract}


speaking work in the FL, connecting to what happens in everyday life; learning develops beyond the context of the classroom, since learners receive feedback from the tutor about language forms and uses beyond the syllabus of the course; and the granting of autonomy to learners as they can systematise their learning process.

Keywords: electronic resources; interaction; Portuguese-AL

\section{Introdução}

Estar em contato com uma língua estrangeira (LE) tem se tornado relativamente acessível, atualmente, em virtude do desenvolvimento e da popularização de meios eletrônicos, quando se compara a situação atual àquela de alguns anos atrás. Essa facilidade não apenas inclui contextos de viagens, de negócios ou de outras ações que requerem interação presencial, mas estende-se a contextos de ensino de maneira geral e de ensino de LEs em particular. Consequentemente, o(s) contexto(s) de interação passa(m) a ter distintas configurações, estreitando as fronteiras políticas e linguísticas. As possibilidades de interação configuram-se variáveis e amplas com o uso da internet e com os recursos que ela disponibiliza aos usuários. Este é, portanto, um aspecto a ser abordado neste artigo.

Outro aspecto a ser contemplado diz respeito à configuração que o ensino e a aprendizagem de português como LE têm tomado. Essa nova configuração resulta de algumas características dos interessados, incluindo aprendizes que já sabem outras LEs e o português já não é a primeira LE com a qual eles têm contato, como também aprendizes que convivem em contexto multilíngue, o que permite conceber a Língua Portuguesa como uma LE-adicional (ROTTAVA e DA SILVA, 2011) ${ }^{1}$.

Portanto, esses dois aspectos interligados constituem o foco deste estudo, cujo objetivo é analisar a produção oral e escrita de aprendizes de português LE-adicional. Os dados para a análise são o resultado de tarefas realizadas em ambiente virtual: live chat (batepapo virtual) em sala de aula - ambiente de bate-papo disponível no

\footnotetext{
1 A coleta de dados e as análises preliminares foram realizadas em 2008. Porém, somente em 2011 os resultados dessa pesquisa foram publicados.
} 
Moodle (website usado pela universidade onde as atividades foram realizadas como parte de seu VLE [virtual learning environment/ambiente de aprendizado virtual]) e 'talking photos' (fotos com narrativa oral) - narrativas orais produzidas com recursos da internet (programa fotobabble). As perguntas de pesquisa de que se pretende dar conta são: quais as dificuldades recorrentes na produção dos aprendizes; quais as estratégias utilizadas pelos aprendizes ao se depararem com alguma dificuldade para atingir seus propósitos. Desse modo, a contribuição deste artigo é indicar quais dimensões das tarefas realizadas otimizam a aprendizagem.

O artigo está organizado em quatro seções. A primeira trata da conceitualização teórica que orienta este estudo; a segunda descreve o contexto de pesquisa, o perfil dos participantes, as tarefas desenvolvidas e implementadas; a terceira concentra-se na análise dos dados e na discussão dos resultados e a última traz algumas considerações finais.

\section{Conceitos teóricos que orientam essa reflexão}

\subsection{A interação em ambiente eletrônico}

Meios eletrônicos ${ }^{2}$ de certa maneira sempre estiveram presentes no ensino de línguas, quer seja pelo uso de fitas cassetes na abordagem de ensino da gramática-tradução, quer seja pela internet e por recursos que ela oferece, recorrentes na abordagem comunicativa de ensino. Warschauer e Meskill (2000) detalham esses recursos, salientando o papel que desempenham em uma ou em outra abordagem de ensino e discutem, como exemplo, a função que os laboratórios de línguas tinham na aprendizagem da pronúncia e na automatização de estruturas gramaticais de uma LE. Sem dúvida, a importância desses recursos era decorrente da abordagem de ensino seguida pelo professor e das escolhas de quais recursos acreditava serem apropriados para

\footnotetext{
2 O termo "meios eletrônicos" é usado neste artigo para se referir ao uso de recursos tais como fitas cassetes, fitas de VHS, populares antes da era da internet. O termo "recursos eletrônicos", por sua vez, contempla a inclusão da internet.
} 
instrumentalizar os aprendizes para que pudessem desenvolver a competência comunicativa na LE. Porém, a responsabilidade pela seleção e organização do material era do professor, ou seja, ensino centrado no professor.

A integração entre ensino de LE e meios eletrônicos passa a ter mais importância nos anos 80 e 90 (WARSCHAUER e MESKILL, op.cit.) com abordagens de ensino de base comunicativa (CANALE e SWAIN, 1980). Na abordagem comunicativa, conceitos de interação e de materiais autênticos são recorrentes. O conceito de interação diz respeito ao modo como a linguagem funciona em distintos contextos dos quais os sujeitos fazem parte. Esse funcionamento se dá pela constituição de momentos organizados de interação face a face, de interação instada pelo texto escrito (na leitura ou na escrita) e de interação mediada por meios eletrônicos. Portanto, o pressuposto que orienta qualquer interação é a realização de uma ação para conseguir algo, fazer um acordo, atingir um objetivo, sempre envolvendo práticas discursivas e usos de linguagem situados socioculturalmente.

Por sua vez, materiais autênticos compreendem jornais, revistas, livros, panfletos que circulam no cotidiano, música, programas de rádio e de TV e, recentemente, páginas da web, embora o conceito de documento autêntico suscite muitas controvérsias. Esses materiais possibilitam que qualquer sujeito (aprendiz ou não) desempenhe papéis discursivos na interação de acordo com as condições de produção e de circulação em uma comunidade sociocultural (PACHECO, 2006).

Desse modo, compreender a interação em suas mais diversas possibilidades e com materiais que podem variar socioculturalmente é seguir uma abordagem de ensino de base sociocultural (LIGHTBOWN e SPADA, 2006). Isso significa, no ensino de LE, levar em conta aspectos sociais da linguagem, oportunizando aos aprendizes interagirem com o outro (aprendiz ou não da língua) na LE fora da sala de aula. Nessa visão, os meios eletrônicos, em especial a internet, têm sido recursos aliados ao processo, uma vez que aumentam as oportunidades de interação do grupo e, de acordo com Warschauer e Meskill (2000), "permite[m] discussões sincrônicas (em tempo real) e discussões assincrônicas por email, lista de discussão, sites de relacionamentos, dentre outras" (p.7), embora, segundo os autores, essa instrumentalização tenha sido criticada por ser vista por 
professores e por pesquisadores da área como uma alternativa artificial à interação face a face. Salienta-se que o fato de se conceber a interação para além de uma ação presencial significa compreender que esta pode ser mediada por outros recursos, dentre os quais, os eletrônicos.

Com esses recursos, oportuniza-se aos aprendizes, em particular aos mais tímidos em sala de aula, participarem de maneira colaborativa das tarefas, além de serem contemplados temas polêmicos que podem ser mais bem discutidos com a participação de todos. Ademais, o fato de os aprendizes estarem lendo/relendo ou terem a oportunidade de responder por escrito às mensagens permite-lhes incorporarem usos ou construções linguísticas que foram produzidas pelos seus interagentes à sua produção e assim expandir a aprendizagem. Portanto, ao interagir face a face ou por meio eletrônico, os aprendizes acessam o léxico e as construções gramaticais na LE que variam em complexidade, em uso e de acordo com a situação: colegas de sala de aula, trabalho, amigos, sujeitos de seu entorno social, sujeitos distantes, sujeitos de costumes distintos, sujeitos que vivem em outros países, dentre outras possibilidades ${ }^{3}$.

Outras formas de interação por meio eletrônico, embora não seja o foco deste artigo, dizem respeito ao ensino a distância, à publicação do que é produzido pelos aprendizes em LE e à construção de páginas na web (WARSCHAUER e MESKILL, 2000). O conceito de ensino a distância tem sido controverso: desde a ideia de ensino que é previamente determinado por um currículo e controlado a distância até aquele que complementa o ensino presencial por meio de recursos eletrônicos disponíveis para expandir o tempo de interação e o contato entre professor/aprendiz e aprendiz/aprendiz, iniciado em sala de aula e estendido a outros contextos. Em outras palavras, esse tipo de ensino pode ser um recurso para aumentar o tempo de ensino e de aprendizagem, pois na realização de uma tarefa online, por exemplo, o aprendiz não precisa esperar pela aula seguinte para obter feedback (retorno) de sua atividade; o professor, por sua vez, pode enviar o

\footnotetext{
${ }^{3}$ Um exemplo de oportunidades de aprendizagem de LEs em ambiente virtual pode ser observado em http://www.livemocha.com, que compreende uma grande comunidade mundial de aprendizes de idiomas.
} 
retorno para o aprendiz eletronicamente (ou algo similar) ${ }^{4}$, portanto, resultando em trocas interativas além da sala de aula.

Ademais, o aprendiz, com o acesso a recursos eletrônicos, passa a ter a oportunidade de interagir com inúmeras pessoas falantes daquela LE que está aprendendo - em seu meio ou em outros. São possibilidades que antes, sem tais ferramentas, seriam reduzidas e/ou teriam custos elevados porque os interessados em aprender uma LE precisariam viajar para outro(s) lugar(es). Em suma, os meios eletrônicos representam maneiras pelas quais o aprendiz mantém contato com uso na LE em situações menos prováveis de se concretizarem em sala de aula.

Por último, cabe salientar que os meios eletrônicos não devem ser vistos como uma abordagem de ensino, nem como substituição do professor; ao contrário, incorporá-los ao ensino de língua exige mais criatividade. Eles precisam ser vistos como uma maneira de integrar a tecnologia ao ensino de língua de modo a ampliar a frequência e a qualidade e quantidade de interação linguística e intercultural, uma vez que a tecnologia é parte do cotidiano dos aprendizes e com a qual muitos deles lidam diariamente.

Conforme observa-se, os meios eletrônicos requerem, no processo de ensino e de aprendizagem, um aprendiz co-responsável pelo insumo que recebe e com o qual interage. O aprendiz não é apenas um sujeito que recebe passivamente o conhecimento, mas, recorrendose à metáfora de Zhu (2010, p. 67) "um arquiteto ativo", realizador e independente (PACHLER, 2002), aquele que transforma o insumo, advindo das interações do cotidiano, em conhecimento sistematizado na LE.

Todavia, a relação entre ensino de LE e meios eletrônicos não é apenas positiva. Zhu (2010) destaca incompreensões do papel desse recurso, dentre as quais, a autora acredita que o simples fato de usar tais recursos não significa que seja seguida uma abordagem de ensino em que o aprendiz é também co-responsável pelo processo. Nesse sentido, a função do professor ainda permanece crucial. E, mais

\footnotetext{
4 Tem-se desenvolvido websites nos quais há ferramentas que possibilitam ao professor fornecer feedback por meio de gravações, vídeos ou em outras formas, se desejar. Exemplos destes websites são o Vocaroo e o Jing' - programas eficientes e usados para esse fim.
} 
importante, em vez de ter um papel apenas onipresente, o professor passa a ter um papel onisciente, em que age como um observador constante (como em um 'big brother') e acompanha a produção do aprendiz, especialmente oral, para além da sala de aula.

Contudo, se o professor não tiver clareza das razões pelas quais incorpora os recursos tecnológicos em suas aulas, podem surgir problemas de natureza diversa, dentre os quais: primeiro, o aprendiz pouco vai aperfeiçoar sua aprendizagem, pois não vê razão para usar determinado recurso, e o professor pouco irá acompanhar tais tarefas; segundo, o professor superestima a capacidade do aprendiz em lidar com os recursos tecnológicos, acreditando que ele sabe o que fazer, como fazer e quando fazer e, acima de tudo, que é responsabilidade do aprendiz desenvolver suas estratégias de aprendizagem e, como consequência, o professor deixa de ter a função de ensinar; terceiro, é crucial que o professor tenha preparação e saiba usar os recursos eletrônicos, pois não basta ter ferramentas inovadoras, se não souber explorá-las de forma eficiente; por último, é preciso considerar a tecnologia um recurso complementar para a otimização do aprendizado e para alavancar a aprendizagem que complementa o que é ensinado/aprendido no contexto de sala de aula. O professor não é alijado de seu papel de instrutor, de coparticipante e, acima de tudo, de interagente especializado que acompanha as atividades, oferece feedback e sistematiza o ensino com base na identificação dos problemas verificados nas tarefas, objetivando mostrar aos aprendizes o que e porque determinado uso não é adequado. E, desse modo, indica em quais aspectos os aprendizes precisam desenvolver e se empenhar na aprendizagem para que percebam as razões do uso de uma determinada tarefa como parte do aprendizado da LE.

Além disso, uma sugestão para minimizar divergências como as descritas anteriormente, de acordo com Zhu (op. cit.), é que os cursos recorram a tarefas de ensino diversificadas e, da mesma maneira, escolham quais recursos eletrônicos usar. Portanto, é papel do professor equilibrar a seleção desses recursos, saber em quais assuntos ou com qual ênfase deve utilizá-los - leitura, escrita, produção ou compreensão oral. E, finalmente, também é função do professor criar condições de ensino e de aprendizagem, assim como combinar tarefas de sala de aula às extracurriculares. 


\subsection{Língua Portuguesa como LE-adicional}

A recorrência ao termo que define a Língua Portuguesa como LE-adicional é recente (ROTTAVA e DA SILVA, 2011; ROTTAVA, 2008 e 2009). O termo refere-se aos contextos nos quais o português é mais uma língua dentre outras que o aprendiz está aprendendo ou usa em situações de interação no seu cotidiano. Em função da expansão da Língua Portuguesa por motivos políticos, econômicos e culturais, a demanda de interessados em aprender a língua, também por motivos diversos, tem se expandido (ROTTAVA e DA SILVA, 2011). Esse aumento significa que falantes de línguas diversas e com experiências de aprendizagem prévias com outras LEs têm mudado a configuração do ensino e da pesquisa sobre português LE.

Estudos que focalizam o português como LE-adicional, embora ainda com resultados não comparados a contextos diferenciados, têm sugerido que o fato de se tratar de uma LE-adicional significa que é preciso considerar certas variáveis como fatores importantes no ensino e na aprendizagem de LEs. Para entender um pouco mais dessas variáveis, relatam-se, no que segue, alguns dos resultados de estudos que mostram a importância de se levar em conta o contexto de ensino cuja língua é uma LE-adicional.

Um primeiro estudo, realizado por Rottava e Da Silva (2011) com aprendizes de português como LE-adicional, cujos dados foram coletados em contexto multilíngue, investigou crenças de aprendizagem e sua relação com o conhecimento linguístico prévio, investigando as experiências de aprendizagem com outras LEs, e comparando aprendizes monolíngues a multilíngues. Os resultados, em termos gerais, indicaram haver certa convergência entre o perfil do aprendiz e suas crenças relacionadas ao fato de terem tido a oportunidade de aprender uma ou várias LEs, além de estarem em contexto multilíngue. Quando comparadas as crenças de aprendizes multilíngues e monolíngues, observou-se que ambos os grupos são motivados para a aprendizagem e, portanto, uma motivação integrativa os move à aprendizagem; as experiências prévias como aprendizes de outras LEs contribuíram no processo. Isso indica que a variável LEadicional é um fator relevante na abordagem de ensino.

Em outro estudo, Rottava (2009) investigou a produção oral e escrita desenvolvida por aprendizes de português LE-adicional, 
buscando entender a relação entre identidade (NORTON, 1995) e "vozes" (BAKHTIN, 1986). Os resultados indicaram que o contexto de LE-adicional contribui para a percepção/construção das "vozes" dos aprendizes no processo de aprendizagem dessa língua. Em outras palavras,

as vozes parecem refletir o contexto no qual os aprendizes vivem, o conhecimento textual e discursivo relativo à organização textual que produziram, a competência linguísticocomunicativa na L3 ou na LE adicional, a possibilidade e o contexto em que eles têm oportunidade de interagir na línguaalvo ou em outras LEs, assim como regras e normas que advêm da língua materna ou do conhecimento de outras LEs pelos participantes (ROTTAVA, 2009, p. 96).

E, finalmente, o estudo produzido por Rottava e Da Silva (no prelo), diz respeito à influência interlinguística em textos escritos produzidos por aprendizes de português LE-adicional. Os autores destacam haver variáveis intervenientes nessa influência no processo de escrita. Para tanto, analisam aspectos gramaticais na produção escrita e investigam como os aprendizes os usam em português LEadicional. Os dados consistiram de produções escritas por onze alunos, considerando-se a influência interlinguística e a(s) língua(s) estrangeira(s) que tem(têm) aprendido. Os resultados, resumidamente, incluíram cinco aspectos: primeiro, a influência interlinguística na escrita foi de natureza diversa; segundo, a proficiência na língua alvo e as ocorrências de influências de outras LEs, particularmente de línguas próximas, apresentaram alguma relação. Terceiro, com relação ao léxico, percebeu-se que as influências precisam ser vistas como um continnum que incluem instâncias de empréstimos e transferências lexicais. Essas instâncias, quando feita uma distinção entre forma e significado, permitiram identificar o tipo de informação que pode ser transferida da L1 ou de uma LE. Quarto, mais dados seriam necessários para entender em que medida o conhecimento gramatical na L2 pode ou é estendido para a LE-adicional. E, finalmente, o estudo encontrou certa dificuldade para categorizar as influências linguísticas particularmente quando a língua materna dos aprendizes era uma língua tipologicamente próxima. A conclusão principal foi quanto à 
dificuldade em se verificar o exato papel que cada língua - materna, L2, L3, L4 e assim por diante, exerce nesse processo.

\section{Desenho da pesquisa}

\subsection{Contexto de pesquisa e perfil dos participantes ${ }^{5}$}

Português como LE (PE-LE) é oferecido como parte do curso de bacharelado (BA) em Hispanic Studies, mas é aberto a alunos de outros cursos como matéria eletiva/opcional, da universidade britânica onde as atividades são base dos dados para esta pesquisa. São oferecidos quatro níveis de português: $1 \mathrm{~A}, 1 \mathrm{~B}, 2 \mathrm{~A}$ e $2 \mathrm{~B}^{6}$, sendo que cada nível consiste de 30 hora/aula durante um 'termo' acadêmico, o qual tem duração de 10 semanas de aula e duas reading weeks ('semanas de leitura'). O total das horas é dividido em três aulas por semana, sendo uma delas no laboratório de línguas.

Para este estudo, os dados são de dois grupos de alunos matriculados no curso de português para iniciantes, 1A, na universidade em questão. Todos os aprendizes, com exceção de apenas um dos sujeitos, nunca haviam participado de curso de português em contexto formal. A coleta de dados ocorreu durante o primeiro mês de aula.

Fizeram parte deste estudo dezesseis aprendizes de português como LE-adicional, sendo quatro do sexo masculino e doze do feminino. A idade média dos participantes é vinte anos, com exceção de um sujeito de 55 anos. Todos afirmam saber mais do que uma LE e, portanto, o português é uma LE-adicional para esses aprendizes. O quadro 01 resume essas características:

\footnotetext{
${ }^{5}$ Para a obtenção de dados mais detalhados para delinear o perfil dos participantes foi aplicado um questionário de uma página, elaborado em inglês devido ao nível de proficiência dos alunos. Ele continha perguntas abertas e fechadas. Nele, os participantes mencionaram seus dados pessoais, listaram as LEs que dizem saber e o nível de proficiência em cada uma, além das razões pelas quais querem aprender português: amigos, relações familiares, cultura, turismo, entre outras.

${ }^{6}$ Os níveis dos cursos seguem o Common European Framework for Languages (CEFLs). Para relação entre o ensino de português e o documento (ver Da Silva, 2010).
} 


\begin{tabular}{c|c|c|c|c|c|c|c}
\hline Suj & Idade & L1 & LE-1 & LE-2 & LE-3 & LE-4 & LE-5 \\
\hline A1 & 26 & russo & inglês & italiano & & & \\
\hline M1 & 19 & inglês & francês & italiano & & & \\
\hline E1 & 18 & inglês & espanhol & francês & italiano & & \\
\hline J1 & 21 & alemão & francês & inglês & espanhol & & \\
\hline S1 & 18 & armênio & francês & inglês & holandês & & \\
\hline M2 & 21 & alemão & inglês & francês & & & \\
\hline M3 & 20 & inglês & francês & espanhol & & & \\
\hline A2 & 18 & inglês & francês & espanhol & & & \\
\hline G & 19 & inglês & espanhol & & & & \\
\hline M4 & 19 & inglês & francês & alemão & espanhol & & \\
\hline S2 & 19 & inglês & espanhol & francês & & & \\
\hline T & 55 & inglês & francês & italiano & espanhol & alemão & catalão \\
\hline R & 27 & polonês & inglês & francês & russo & alemão & \\
\hline E2 & 19 & inglês & grego & espanhol & francês & italiano & \\
\hline J2 & 18 & inglês & francês & alemão & & & \\
\hline K & 19 & lituano & inglês & francês & alemão & & \\
\hline
\end{tabular}

Quadro 01 - perfil dos participantes

Por elencar as línguas que os participantes afirmam saber, pode-se sugerir que se trata de um contexto multilíngue, pois eles estão inseridos em um contexto cuja língua materna é o inglês, mas essa não é a língua materna de uma boa parte dos sujeitos (37,5\%). Esse contexto permite que os aprendizes tenham contato constante não apenas com distintas LEs, mas com a cultura de seus falantes/usuários (modos de vida, percepções, crenças de aprendizagem) ${ }^{7}$. Por essa razão, o contexto é também reconhecido como um contexto multicultural.

\subsection{Tarefas online desenvolvidas e implementadas}

Os dados analisados resultaram de três tarefas online em que os sujeitos participaram: uma atividade de bate-papo em contexto de

\footnotetext{
${ }^{7}$ Bourdieu (2001) salienta que todo sujeito revela crenças e percepções em virtude do meio em que vive, denominado de "habitus". Esse modo de viver constitui a cultura de um povo ou de uma comunidade.
} 
aula no laboratório de línguas usando o recurso chat disponível na plataforma online Moodle; e duas atividades extra-classe usando o recurso fotobabble disponível na web: na primeira, o aprendiz deveria falar sobre si ou sobre uma pessoa famosa e, na segunda, o aprendiz teria que falar sobre sua casa ou imaginar como seria. A atividade de bate-papo consistiu de duas interações envolvendo os aprendizes do nível 1A, com duração média de 22 minutos. $O$ objetivo foi proporcionar aos aprendizes a oportunidade de interagir com os colegas de modo que pudessem usar a LE, assim como vocabulário aprendido até então. Deveriam, principalmente, falar de si mesmos, do ambiente, das pessoas de seu convívio e de seus planos para o futuro. Além disso, o propósito foi incentivar os aprendizes a buscar oportunidades de uso da língua, sem que tenham que depender somente de atividades realizadas no contexto de sala de aula, seja usando a plataforma virtual da universidade, Moodle, ou outros meios disponíveis na internet para aperfeiçoar suas habilidades linguísticas na LE, assim tornando-se um "arquiteto ativo" (ZHU, 2010) e, portanto, desenvolvendo sua autonomia como aprendiz. O professor propôs a tarefa e deixou que os alunos interagissem, apenas intervindo quando solicitado para esclarecer dúvidas ou responder perguntas dos aprendizes. Além disso, o professor teve a função de observar a atividade e tomar notas da interação a fim de sistematizar as dificuldades indicadas pelos aprendizes para, a posteriori, propor atividades de revisão; ou seja, o professor teve o papel de facilitador e implementador da atividade e também o de dar feedback aos aprendizes, mas sem tirar a autonomia destes durante e após a tarefa.

Com relação à interação realizada em chat, são analisadas duas situações. Na primeira, estiveram envolvidos doze participantes, e a duração foi de vinte e dois minutos; por sua vez, na segunda, fizeram parte três participantes e a duração foi de vinte e sete minutos.

As outras duas tarefas online foram realizadas extra-classe por meio do recurso fotobabble. Essa ferramenta possibilita ao usuário baixar fotos e falar sobre elas ao mesmo tempo em que é gravado o que está sendo dito. Terminada a gravação, o usuário poderá compartilhar sua produção com outras pessoas, através de email ou fornecendo o link da gravação na web para a outra pessoa. No caso das atividades realizadas pelos aprendizes de português, todas foram 
disponibilizadas na plataforma Moodle. Quatorze aprendizes realizaram a tarefa 1 e também a tarefa 2 .

\section{Análise dos dados e discussão dos resultados}

Os dados são analisados, separadamente, de acordo com o recurso eletrônico recorrente, iniciando-se pelo chat e, na sequência, os dados gerados no recurso do fotobabble. Buscar-se-á entender em que medida esses recursos eletrônicos otimizam o processo de aprendizagem de português LE-adicional.

\subsection{O recurso 'chat' na plataforma online Moodle}

Com relação à interação realizada por meio de chat, as duas situações serão analisadas separadamente. $\mathrm{Na}$ primeira situação interativa no chat, os participantes produziram 185 turnos em 22 minutos de interação, cuja média de participação de cada aluno, por turno interacional, foi de oito turnos. Essa interação ocorreu como uma das tarefas realizadas em sala de aula, onde os aprendizes tinham acesso a computadores. O professor sugeriu a tarefa, sem orientações pontuais a respeito do que deveriam falar nem com relação à forma da língua que deveriam usar, apenas instruiu como acessar o programa e salientou que, com esse recurso, poderiam, por exemplo, conhecer melhor os colegas e falar sobre família, preferências ou planos. Por sua vez, o professor, observou as interações de seu computador, anotando aspectos que seriam posteriormente comentados com o grupo e/ou sistematizados em aula subsequente.

No trecho inicial da interação, observam-se as diferentes formas de cumprimento e o modo como participaram da situação comunicativa.
(01)
04 11:09 G.: ola
05 11:09 E1: ola A2!

\footnotetext{
8 A numeração representa o turno de interação que está sendo objeto de análise. Relembrando, a tarefa toda está organizada em 185 turnos.
} 
A interação em ambiente eletrônico no ensino de PLE

06 11:10 J1: Oi M4, tudo bem?

07 11:10: M1 has just entered this chat

08 11:10 M2: Bem obrigado, et voce??

09 11:10 T.: o que voce fazer fins de semana?

$10 \quad$ 11:10 M4.: Otimo obrigado, e tu?

11 11:10 A2: E1, tudo bem?

12 11:10 E1: sim, tudo bem, e voce?

13 11:11 J1: legal! que voce vai fazer neste fim de semana?

$14 \quad 11: 11$ T.: M2?

15 11:11 M2: sim

16 11:11 M4: Eu vou visitar minha familia, e voce?

No fragmento (01), cada aprendiz teve contato com usos na LE e foi requerido responder ao interagente que a ele se dirigiu (1.05, 06, 11) ou atender a interpelação do colega para que participasse da interação (1.14) e, simultaneamente, acompanhar na tela as demais interações que ocorriam. Representou, portanto, uma oportunidade genuína em que o aprendiz precisou interagir e saber quem seria seu interlocutor imediato e qual informação deveria lhe oferecer, ou seja, precisou agir com certa rapidez para não deixar o interagente esperando por uma resposta impedindo que a rolagem da tela fizesse com que a informação em foco fosse perdida ou esquecida.

$\mathrm{Na}$ sequência desse momento inicial, cuja interação caracterizou-se pelos cumprimentos e apresentação pessoal, a continuidade envolveu o relato de algo do cotidiano que tivesse realizado ou em realização ou ainda que pretendesse fazer.

11:12 M3.: M4,o que você vai fazer no próximo fim-desemana?

21 11:12 M2: Nao, eu vou visitar minha familia Dezembro

22 11:12 J2: eu vou cantandar em cathedral de canterbury

23 11:12 J1: eu penso que vou a Franca para ver a amigos, mas eu nao sei si eu posso ir a causa de os strikes ${ }^{9}$

24 11:12 A2: estou bem obrigada! o que você vai fazer fim-desemana?

25 11:12 M2: Eu vou visitar minha amigos em Hollanda

${ }^{9}$ Greve dos meios de transporte que acontecia na época em que a atividade foi realizada. 
$26 \quad$ 11:13 G.: tudo bem obrigado, e tu?

27 11:13 E1: vou fazer compras con minha amiga que se chama poppy em londres

28 11:13 J2: eu vou dancar com mes amigos

29 11:13 T.: onde em Hollanda?

$30 \quad 11: 13$ G.: M1?

31 11:13 M4: $O$ wow ${ }^{10}$... voce e fortunada

O fragmento (02) requereu dos interagentes pensar em usos que potencialmente refletissem o sentido que pretendiam construir, como em "cantandar" (1.22), "ir a causa de os strikes" (1.23), "minha amigos" (1.25) e "fortunada" (1.31), indicando as suas estratégias para dar conta de aspectos do vocabulário ainda não usado em outras situações ou não aprendido, permitindo-lhes extrapolar/testar construções na LE. Além disso, o que parece também corroborar é a transparência entre as LEs como por exemplo "minha amigos" (1.25) e "fortunada" (1. 31), a interferência interlinguística parece ser significante e, em tais situações, ela é positiva, na medida em que os interagentes recorrem a tais formas linguísticas e esperam ser compreendidos. Por outro lado, nem todos os aprendizes têm domínio de línguas (LM ou LEs) que sejam transparentes linguisticamente e as estratégias utilizadas parecem não funcionar da mesma maneira. Desse modo, esse resultado pode estar indicando que, dentre as dificuldades recorrentes nesse tipo de interação e no início do curso, os aprendizes correm o risco de não serem compreendidos. Porém, assim como no cotidiano, os riscos de mal entendidos são inerentes a toda e a qualquer situação e em qualquer língua.

O trecho que segue permite observar mais detalhadamente essa possibilidade de testar usos na LE sem previamente terem sido expostos a regras.

(03)

41 11:14 M2: Em Leiden, $T$.

42 11:14 T.: eu vou tambem a londres a ski show

43 11:14 S2: еи vou a casa e depois eu vou a sheffield visitar meus amigos

44 11:14 M2: Oi J1:) Sim et voce??

${ }^{10}$ Interjeição correspondente a 'uau' em português. 


\begin{tabular}{|c|c|}
\hline 45 & $\begin{array}{c}\text { 11:15 G.: bem, o que voce vai fazer no proximo fim de } \\
\text { semana M1? }\end{array}$ \\
\hline 46 & 11:15 M4: ola, S1... como vai voce? \\
\hline 47 & $\begin{array}{c}\text { 11:15 A2: vou ir al bar com mis amigos, e vamos ir a } \\
\text { restaurante :) }\end{array}$ \\
\hline 48 & 11:15 M3.: S1, o que voce vai fazer? \\
\hline 49 & 11:15 E1: que se chama el restaurante? \\
\hline 50 & 11:15 S1: tudo bem! e voce? \\
\hline 51 & $\begin{array}{l}\text { 11:16 J1.: bem! a semana que ven eu vou ter minha reading } \\
\text { week }{ }^{11} \text {, assim bem legal! }\end{array}$ \\
\hline 52 & 11:16 M2: oi J1, O que voce vai fazer a Natal? \\
\hline 53 & 11:16 S1: eu vou a londres para sair com amigos \\
\hline 54 & 11:16 T.: onde esta Leiden? perto Amsterdam? \\
\hline 55 & 11:16 J2: Eu vou visitar um amigo em Leicester. \\
\hline- & 11:16 M1: vou jogar futebol. e tu? \\
\hline
\end{tabular}

Observando os três fragmentos, pode-se sugerir que os aprendizes tiveram a possibilidade de testar usos da LE e o acesso ao vocabulário que seus interagentes conheciam. Constituiu-se, portanto, em uma possibilidade para sistematizar usos na LE, pois, além do uso, observou-se que os participantes foram instados, pela interação: a usar distintos tempos verbais, em particular o presente e o futuro, assim como formas do passado; a usar estruturas interrogativas diversas, com ou sem a recorrência a pronomes interrogativos; a usar formas distintas dos pronomes pessoais (tu, você ${ }^{12}$ ), advérbios de tempo, orações justapostas ou coordenadas, orações complexas, pela construção de relativas em "vou fazer compras con minha amiga que se chama poppy em londres" (1.27). Sem dúvida, os alunos abordaram situações reais e, nesse sentido, o papel do professor foi crucial para a sistematização de tais construções. Desse modo, propiciou aos aprendizes ampliarem esses usos, por receberem feedback do professor sobre suas

\footnotetext{
${ }^{11}$ Em cada curso de 10 semanas, duas são reservadas para os alunos dedicarem-se à leitura ou para realizarem trabalhos extra-escolares. Essa semana denomina-se reading week ou 'semana de leitura' em uma tradução literal.

${ }^{12}$ Estas formas, em algumas LEs que os aprendizes têm contato, por exemplo, a língua francesa e a espanhola representam diferença de formalidade e informalidade. No português europeu isso também acontece, porém isso não ocorre no português brasileiro.
} 
intervenções durante a realização da tarefa, mesmo sem fazer parte da lista de conteúdos programáticos.

O outro chat em que o segundo grupo de aprendizes participou teve duração de vinte e sete minutos e participaram três sujeitos em 110 turnos de interação. Assim, como na interação anterior, os aprendizes tiveram a oportunidade de fazer usos distintos da LE e de observar as opções dos colegas. O que se destaca, no entanto, é que os aprendizes passaram a auto-observar suas construções assim como a dos colegas, fazendo algum tipo de correção.

12:17 R.: K., o que voce gusto fazer em seu tempo livre?

$31 \quad$ 12:17 R.: sou estudante

$32 \quad 12: 17 \mathrm{~K} .:$ Onde trabalha o cozinheiro, E2?

33 12:17 E2: sou estudante, tambem.

34 12:18 E2: o cozinheiro trabalha en um restaurante.

35 12:18 E2: no restaurante

36 12:18 K.: Gusto ler.

37 12:19 R.: E2, voce gusta de dansar?

38 12:19 E2: K., gosta de morar em Canterbury?

39 12:19 K.: Eu gosto de ler.

$40 \quad$ 12:19 E2: nao, nao gusto de dansar

41 12:19 E2: *gosto

42 12:20 R.: dancar,desculpe:)

O fato de terem contato com usos e formas da LE utilizadas pelos colegas, permitiu, portanto, que interagissem não apenas com os colegas, mas se auto-corrigissem (1.34-35), usando a forma adequada para indicar aos colegas a não apropriação, como em "gusto" (1.36 e 40), "gusta" (1.37), reiterado pelo colega por "gosta" e "gosto" (1.38 e 39) e finalmente incorporado (1.41). Em todos os casos, não houve a interferência do professor, embora ele tivesse acesso em tempo real do que ocorria na interação de todos.

A seguir, serão apresentados e analisados os dados gerados via fotobabble, desses dois grupos de aprendizes. Desse modo, pode-se entender mais claramente as estratégias usadas por esses aprendizes ao produzir oralmente em português LE-adicional. 


\subsection{O recurso fotobabble}

Relembrando a definição apresentada no item 'desenho de pesquisa', fotobabble é uma ferramenta disponível na web que possibilita ao usuário baixar fotos ou imagens e incluir explicações/comentários em áudio a respeito delas ${ }^{13}$. Após a inclusão da foto e posterior gravação, as informações podem ser compartilhadas online (via email ou link em página da web). Para melhor entender, a figura que segue, página web, feita usando o recurso da tela de impressão (PrintScreen) do computador, ilustra a configuração do referido programa.

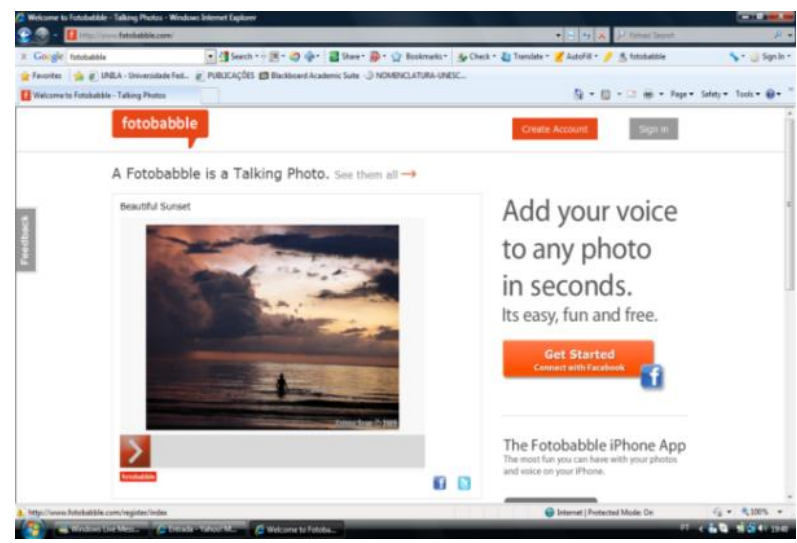

Figura 1-Recurso fotobabble

Diferentemente dos dados anteriores, gerados em chat, na tarefa com esse recurso, os aprendizes poderiam realizá-la em horário extra-classe, tendo a oportunidade de planejar previamente, ouvir a gravação e, se necessário, refazer e regravar para depois publicar online. Foram dois tipos de tarefa: uma requeria a produção de (auto)biografia (própria ou se passando por uma personalidade); a outra requeria a descrição de uma foto de uma residência em que os aprendizes foram instados a descrevê-la como aquela que gostariam de ter.

\footnotetext{
${ }^{13}$ Para esta análise, foram utilizadas apenas imagens/fotos de domínio público.
} 
Comparativamente, as variáveis e as possibilidades que o recurso fotobabble oferece para a realização da tarefa diferem do recurso com chat que foi analisado na seção anterior. Contudo, mesmo reconhecendo-se a influência de tais aspectos, o objetivo é ilustrar as distintas possibilidades que os meios eletrônicos oferecem e como os aprendizes fazem uso desses recursos para otimizar a aprendizagem de LE.

Dessa maneira, passa-se a analisar a tarefa produzida pelo aprendiz G, falante inglês que afirma saber espanhol como LE. Sua escolha foi por uma foto de uma personalidade para criar a autobiografia (Fig. 2).

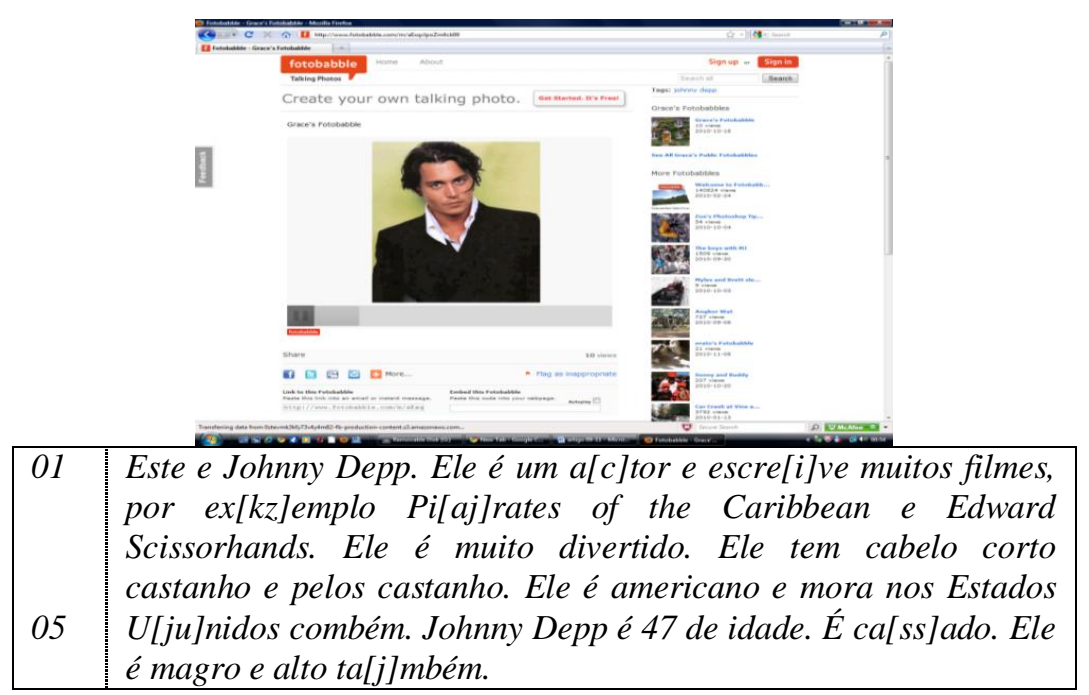

Figura 2 - Produção do aprendiz $G$

Observa-se, na produção desse sujeito, que o fato de ter mais tempo para produzir, provavelmente possibilitou-lhe controlar a produção, alinhando-a a construções da LE e utilizando-se de construções típicas de aprendizes iniciantes, cujas estruturas predominantes incluem sentenças simples e estrutura retórica direta. Pode-se inferir, portanto, que a tarefa permitiu que o aprendiz sistematizasse o que estava aprendendo. No entanto, pelo fato de ainda ser iniciante, sua estratégia foi recorrer a palavras de sua LM: "Pirates 
of the Caribbean e Edward Scissorhands" (1.02-03) visto não saber o léxico na LE e não fazer uma tradução correspondente, utilizando-se de dicionário ou outro recurso. Complementar a isso, buscou adequar as estruturas sintáticas (1.05) de sua LM e, em particular, fonológica (1.02, 05 e 06) e morfológica (1.01) da LE para acomodar a produção de modo que, do ponto de vista de um aprendiz, não ficassem lacunas visíveis ou ideias incompletas.

Outro exemplo produzido por M3, com a mesma personagem, porém com foto diferente, permite discutir detalhadamente em que medida a interferência de uma LE ajuda ou não no processo, como também se é possível inferir a respeito da experiência prévia do participante como aprendiz de LE no processo de aprendizagem agora levado adiante (Fig. 3). Desse modo, o texto foi produzido por M3, que tem como LM inglês e afirma saber duas outras LEs (francês e espanhol).

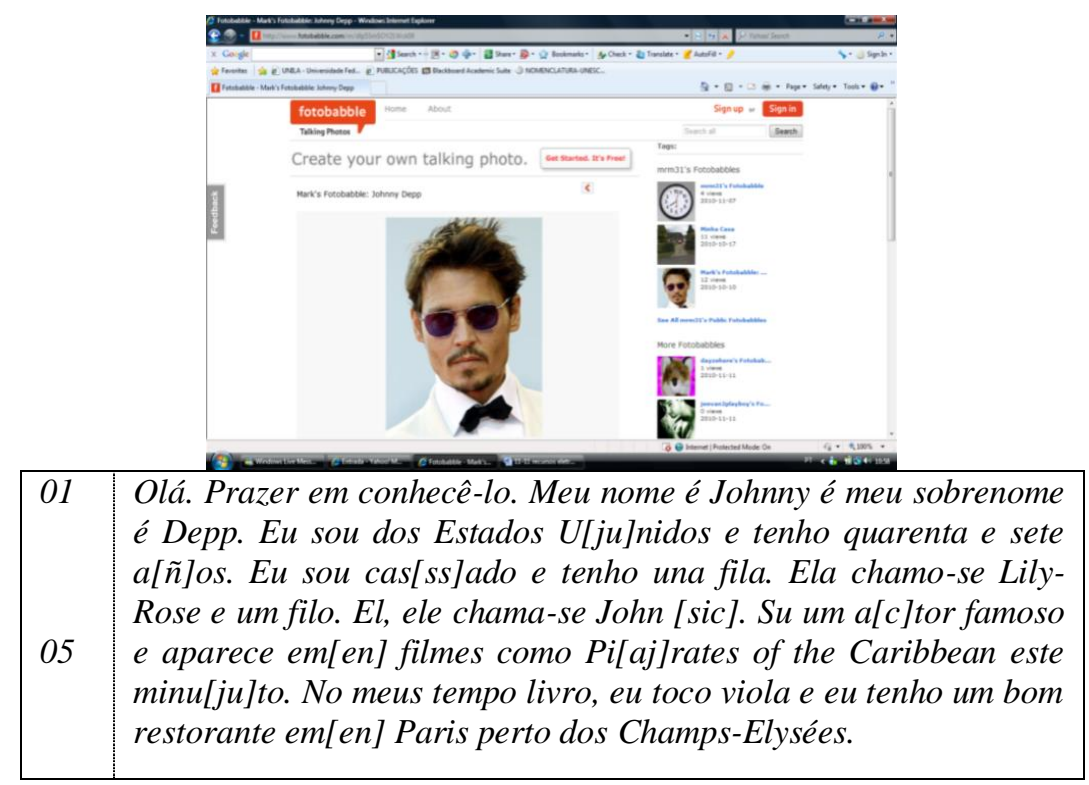

Figura 3 - Produção do aprendiz M3

Comparativamente, nas produções dos dois aprendizes, descrevendo a mesma personalidade, verificou-se que, nesta segunda, 
parece haver uma indicação de melhor proficiência na LE sendo aprendida. Essas pequenas diferenças podem indicar, por hipótese, dois aspectos distintos: as diferenças dizem respeito às características do aprendiz e/ou decorrem do fato deste segundo ter mais experiência como aprendiz de LE. São questionamentos, embora difíceis de apresentar respostas conclusivas e com dados apenas de uma tarefa, que dizem respeito às discussões teóricas relativas à descrição do perfil de um aprendiz de LE adicional (ROTTAVA, 2009).

Para expandir essa discussão, é trazido um exemplo, dessa vez de uma atividade realizada na terceira semana de aula, em que foi requerida do aprendiz a descrição de uma residência (Fig. 4). A atividade apresentada foi produzida pelo aprendiz M3, cuja LM é inglês e afirma saber duas outras LEs (francês e espanhol).

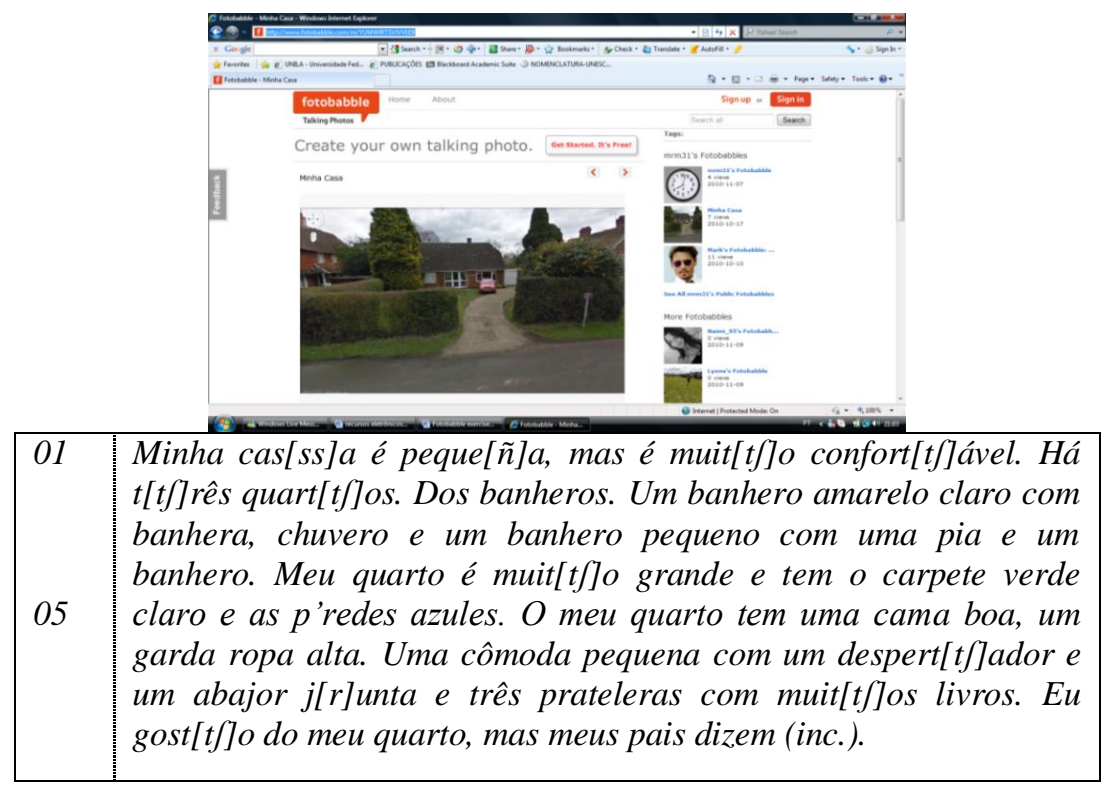

Figura 4 - Produção do aprendiz M3

O texto revela quais dificuldades de natureza formal e de uso se sobrepuseram nesse momento. No trecho, "um garda ropa alta" (1. 06), observou-se que aspectos fonológicos são mais difíceis em virtude 
dos ditongos ${ }^{14}$, por pequenas influências do espanhol, LE que o

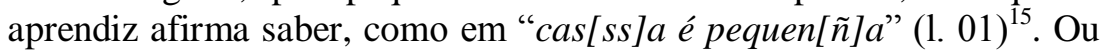
ainda por aspectos morfossintáticos e também de uso, quando resultam em construções como a observada em "Uma cômoda pequena com um despert[t]]ador e um abajor j[r]unta..." (1.06 e 07). Portanto, a tarefa requereu dos aprendizes testar tais construções e, assim, expandir o conhecimento da LE.

Embora se reconheça a dificuldade em haver uma intersecção entre os dois planos - uso e forma - é no uso da LE que são observadas as estratégias a que recorrem os aprendizes. É sobre isso que se discute com base na produção seguinte, realizada por $\mathrm{J} 1$, cuja língua materna é o alemão e afirma saber outras três LEs: francês, inglês e espanhol (Fig. 5).

A produção revelou estratégias do aprendiz para encontrar léxico que lhe permitisse construir um sentido, assim como conhecimento gramatical para elaborar construções relativas à LE de modo adequado. Com elas, o aprendiz indicou que arrisca recorrentemente elaborar construções que necessitariam de adequações morfológicas, quando, por saber o significado genérico de uma

${ }^{14}$ Com relação ao não uso do ditongo, pode-se inferir que se trata de influência da LM do aprendiz - o inglês, cujas regras dessa língua não preveem ditongo em prol de duas vogais grafadas juntas. O som de ditongo é observado, mas seu uso é de acordo com o som das vogais, ou seja, A[ei], i[ai]o[ou], u[ju]. Porém, quando há duas vogais juntas em uma única sílaba, estas normalmente não formam uma ditongação e, em virtude disso, o aprendiz não usa ou não faz a transposição para a LE por, obviamente, não ter em sua LM, mas poderia buscar essa hipótese para transferir da LE que afirma saber. Por exemplo, no caso [ROPA], o aprendiz usa o som do $/ \mathrm{O} / \mathrm{em}$ português, como ele o faz em sua LM - inglês, ou seja, pronuncia somente o som da primeira vogal. Por outro lado, quando se tem $\mathrm{OV}$ em inglês, segue-se uma pronúncia de ditongo que se aproxima à Língua Portuguesa. Em virtude disso, não é possível fazer generalizações no inglês. Todavia, quando se tem $/ \mathrm{OA}$ em uma mesma sílaba, o som será sempre do $\mathrm{O} /\{\mathrm{Ou}\}$, se for usado o som original deste. Ex.: oats [outs].

15 Observe-se em [cassa] e [pequeña] a influência do espanhol. O aprendiz usa a pronúncia do espanhol nas duas ocorrências. Estas construções representam dificuldades para o falante de espanhol ao aprender português, mesmo em níveis mais avançados. Essas dificuldades podem ainda ser exemplificadas por usos tais como: (1) o grafema $\mathrm{S} /$ entre vogais é concretizado pelo fonema $\{\mathrm{ss}\}$ como em espanhol (Bra[ss]il, [ca[ss]a, [ca[ss]ado, etc.), umas das interferências mais frequentes do

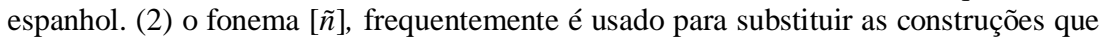
aparecem $/ \mathfrak{h}$, como em peque $[\tilde{n}]$ o. 
palavra, com base em sua entrada lexical no dicionário, pouco a adequa ao contexto de acordo com a sua função sintática: "coisas melhoral". Com aquelas relativas ao léxico, as estratégias do aprendiz consistiram na busca de palavras que pudessem genericamente dar uma ideia do que ele pretendia expressar, como em: "para escutar-me artitisticamente" (1.04), ou no trecho "... espacio para escrever ou fazer coisas melhoral" (1. 05 e 06) ou ainda em "A respeito da arquitectura de imperiódas, vou ter uma grande xxx e algumas cadeiras ariaveles." (1. 09-11), cujas construções funcionam para a maioria das situações, mas não é a regra, como no trecho final quando diz "cadeiras ariaveles".

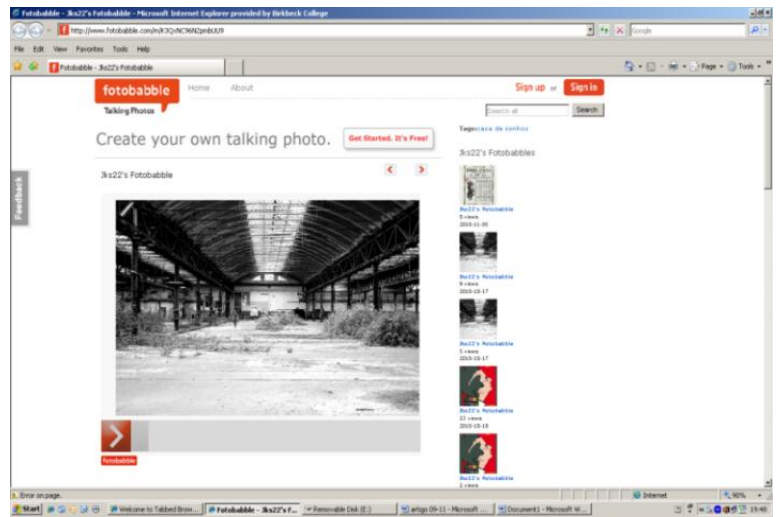

$050 \begin{aligned} & \text { A casa dos meus não ex[kz]iste. Eu não tenho uma visão definitiva } \\ & \text { em que construção ou dum pavilh[a]o ou dum alojamento. Eu sei } \\ & \text { que quero paredes al[j]tas e muito cômodo. O que importa-me mais } \\ & \text { é uma grande área para escutar-me ar[ti]tisticamente. Também vou } \\ & \text { ter uma grande mes[ss] como sempre preciso muito espacio para } \\ & \text { escrever ou fazer coisas melhoral. E mais eu sou cortido de } \\ & \text { coz[ss]inhar e assim eu queria ter uma grande coz[ss]inha, isso } \\ & \text { também permitiria-me convidar a gente. Eu acho que sou um pouco } \\ & \text { claustrofóbia, claustrofóbia, não gosto muito comer soz[ss]inha. A } \\ & \text { respeito da arquite[c]tura de imperiódas, vou ter uma grande xxx e } \\ & \text { algumas cadeiras ariaveles. }\end{aligned}$ Figura 5 - Produção do aprendiz JI

Tais observações indicam características de aprendizes de LEadicional. Contudo, outras dimensões poderiam estar envolvidas, tais 
como: aspectos cognitivos do aprendiz, letramento/formação, cultura de aprender LE, questões relacionadas a quem é esse sujeito ou experiência como aprendiz de LE, em particular, a utilização de recursos eletrônicos. Embora tais questionamentos não se excluam, ressalta-se a hipótese de que o fato de serem aprendizes com experiências em outras LEs permitiu que arriscassem mais e fizessem dessas tarefas, o "andaimento" (scaffolding - VYGOTSKY, 1978, p. 76) de sua aprendizagem (DONATO, 1994).

Para finalizar, apresenta-se um último exemplo desenvolvido por um aprendiz que afirma saber várias LEs. Trata-se de M4, falante de inglês como LM e que afirma saber francês, alemão e espanhol como LEs, respectivamente (Fig. 6).

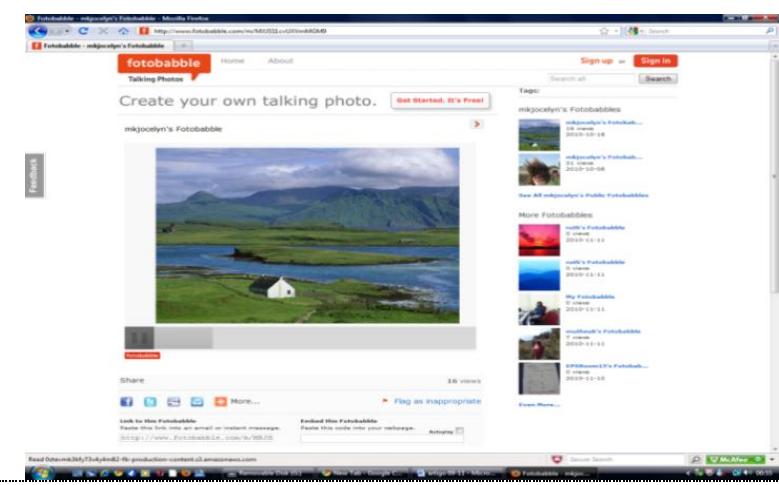

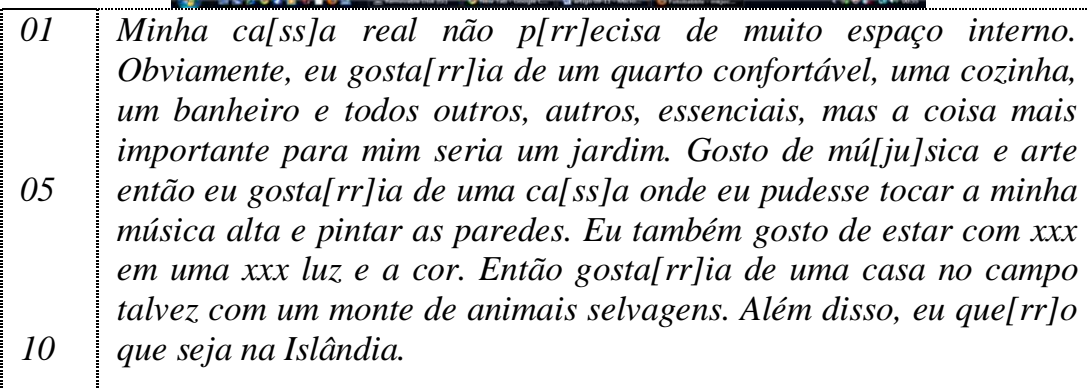

Figura 6 - Produção do aprendiz LM

Esse exemplo contribui para o detalhamento da compreensão da hipótese acima levantada e, sobretudo, permite que se infira em que medida o fato de saber outras LEs melhor explica os resultados 
obtidos. No exemplo, observou-se o uso do subjuntivo 'pudesse'(1. 6), pronúncia marcada no $\mathrm{R}$ (erre) que indicam interferências advindas do francês e, portanto, as LEs que o aprendiz afirma saber é que são observadas no produto deste. Além disso, o aprendiz produziu um texto mais consistente e adequado à LE que está aprendendo em termos de complexidade gramatical: orações opostas pela conexão entre elas ao usar "mas" (1. 03), orações relativas pelo uso de "onde" (1. 05) e elementos coesivos: "então" (1. 08) e "além disso" (1. 09).

\section{Considerações finais}

A análise dos dados, resultantes de tarefas que tiveram como suporte os meios eletrônicos, permitiu compreender alguns aspectos relevantes no processo de aprendizagem de aprendizes multilíngues em situação inicial de contato formal com a Língua Portuguesa. Dentre os principais resultados, destacam-se dificuldades recorrentes e estratégias utilizadas pelos aprendizes ao se depararem com alguma dificuldade durante a realização das tarefas para atingir seus propósitos.

Nas produções dos aprendizes realizadas em chat, verificou-se que elas se caracterizaram por trocas dialógicas em que foi requerido dos aprendizes levarem adiante a tarefa de modo ativo e dinâmico, pois deveriam acompanhar as intervenções dos colegas e participar do processo. Tiveram a oportunidade de observar quais construções na LE foram usadas por seus colegas e, em decorrência dessa observação, incorporá-las em suas produções subsequentes. Essa "incorporação" se deu de maneira diversa entre os interagentes, mas cada um, à sua maneira, desenvolveu competência interativa sob três dimensões importantes: fazer com que a interação flua; lidar com uso da LE em termos quantitativos, e auto-gerenciar suas tentativas, oferecendo alternativas.

Assim como o chat, as tarefas realizadas por meio do fotobabble proporcionaram aos aprendizes oportunidades para usar a língua, porém fora de sala de aula, e acessar a produção dos colegas. Além disso, as tarefas representaram um meio para que os aprendizes interagissem na LE que estão aprendendo. Esse contato ampliou as 
possibilidades de aprendizagem, pois os aprendizes observaram e propuseram adequações às produções próprias e à dos colegas no que tange aos problemas apresentados, relativos a construções inadequadas quanto ao uso e à forma, vocabulário e pronúncia, por exemplo.

Com relação às estratégias utilizadas pelos aprendizes, elas permitiram inferir como e o que eles fazem para expor seu ponto de vista ou levar adiante seu propósito quando se deparam com uma lacuna de vocabulário ou de estrutura gramatical na LE. Outro aspecto relevante com relação às estratégias é que, mesmo sendo aprendizes iniciantes, eles interagiram em tarefa virtual e até se surpreenderam pela quantidade, qualidade e variabilidade de usos da LE que produziram sem terem sidos direcionados a dar continuidade à tarefa, em função de interrupção ou falta de conhecimento na LE.

No que diz respeito ao feedback que os participantes receberam nas tarefas realizadas com os recursos eletrônicos, o que se observou foi que o papel do professor ampliou-se. Este não se restringiu a de um mantenedor do conhecimento e definidor daquilo que é abordado, mas busca indicar as incongruências observadas na interação com esses meios. Dessa forma, é enfatizada a autonomia dos aprendizes porque estes escolhem o que fazer e como fazer. Conclui-se que, em tarefas realizadas com a ajuda de meios eletrônicos, o professor poderia seguir o papel de proponente, observador que acompanha a interação e, por isso, um interagente durante a implementação e/ou realização da tarefa. Assim, o feedback oferecido seria no sentido de sistematizar o processo. Ademais, é importante salientar, no entanto, que o professor deve ter a visão de todo o processo, visto lhe ser requerido que acompanhe a execução das tarefas propostas. Sua função é a de esclarecer dúvidas ainda que estas ocorram fora do contexto de sala de aula, ou seja, o professor assume um papel de apoio.

\section{Referências}

BAKHTIN, Mikail M. Speech genres and other late essays. Texas: University of Texas Press, 1986. 
BOURDIEU, Pierre. A produção da crença: contribuição para uma economia dos bens simbólicos. Porto Alegre: Editora Zouk, 2001.

CANALE, Michael; SWAIN, Merril. Theoretical bases of communicative approaches to second language teaching and testing. Applied Linguistics. v. 1, n. 1, p. 1-47, 1980.

DA SILVA, Antônio. M. Ensino de português língua estrangeira (PLE) por meio de filme: considerações sobre o 'Portfólio Europeu para Línguas (CEFLs)'. Revista Littera, v. 1, n. 1, jan - jul (online), p. 121133, 2010.

DE ANGELIS, Gessica. Third or additional language acquisition. Clevedon; Buffalo: Multilingual Matters, 2007.

DONATO, Richard. Collective scaffolding in second language learning. In: LANTOLF, James P.; APPEL, Gabriela (Orgs.). Vygotskian approaches to second language research. Norwood, NJ: Ablex, p. 33-56, 1994.

ELLIS, Rod. Second language acquisition. Oxford: Oxford University Press, 1997.

HALL, Joan K.;VERPLAETSE, Lorrie .S. The development of the second and foreign learning through classroom interaction. In: HALL, Joan K.; VERPLAETSE, Lorrie S. (org.). Second and foreign language learning through classroom interaction. London: Lawrence Erlbaum Associates Publishers, p. 1-17, 2000.

HALL, Joan K. The role of oral practices in the accomplishment of our everyday lives: the sociocultural dimension of interaction with implications for the learning of another language. Applied Linguistics, v.14, n. 2, p. 145-166, 1993.

LIGHTBOWN, Patsy; SPADA, Nina. How languages are learned. 3. ed. Oxford: Oxford University Press, 2006. 
NORTON, Bonny. Social identity, investment, and language learning. Tesol Quarterly, v.29, n. 1, Spring, p. 9-31, 1995.

PACHECO, Denise G. L. da C. Português para estrangeiros e os materiais didáticos: um olhar discursivo. Tese (Doutorado do Programa Interdisciplinar de Linguística Aplicada) - Faculdade de Letras, UFRJ, 2006.

PACHLER, Norbert. Speech technologies and foreign language teaching and learning. Language Learning Journal, n. 26, p. 54-61, 2002.

ROTTAVA, Lucia. Brazilian Portuguese as foreign/second language: an overview. In: SILVA, Kleber A.; ORTIZ ALVAREZ, Maria L. (Org.). Perspectivas de investigação em linguística aplicada. Campinas, SP: Pontes, p. 245-266, 2008.

ROTTAVA, Lucia. Português como língua terceira (L3) ou língua estrangeira (LE) adicional: a voz do aprendiz indicando identidade. Em Aberto, v. 22, n. 81, p. 81-98, 2009.

ROTTAVA, Lucia; DA SILVA, Antônio M. Beliefs about learning portuguese as a foreign language: multilingual context. In: SILVA, Kleber. A. (Org.). Crenças, discursos \& linguagem - volume II. Campinas, SP: Pontes Editores, p. 130-158, 2011.

ROTTAVA, Lucia; DA SILVA, Antônio M. Influência interlinguística no processo de escrita em L3 ou LE adicional. In: SILVA, Kleber A.; TORRES, Danúsia (Org.). Português como língua (inter) nacional: faces e interfaces. Campinas, SP: Pontes Editores (no prelo).

VYGOTSKY, Lev S. Mind in society: the development of higher psychological processes. Cambridge, MA: Harvard University Press, 1978.

WARSCHAUER, Mark; MESKILL, Carla. Technology and second language teaching and learning. In: ROSENTHAL, Judith (Org.). 
Handbook of undergraduate second language education. Mahwah, NJ: Lawrence Erlbaum, 2000.

ZHU, Zhuo. Applying innovative spirit to multimedia foreign language teaching. English Language Teaching, v.3, n. 2, p. 67-70, 2010.

Recebido em: 06/03/2012

Aceito em: $\quad 03 / 01 / 2013$

Title: Electronic interaction in the teaching of Portuguese as an additional foreign language: the optimization of beginners' learning experience 
A interação em ambiente eletrônico no ensino de PLE 